\title{
Effect of $\mathrm{Au} / \mathrm{SiO}_{2}$ substrate on the structural and optical properties of gallium nitride grown by CVD
}

\author{
A RAMOS-CARRAZCO ${ }^{1, *}$, R GARCIA-GUTIERREZ ${ }^{2}$, M BARBOZA-FLORES ${ }^{2}$, R RANGEL ${ }^{3}$, \\ O E CONTRERAS ${ }^{4}$ and D BERMAN-MENDOZA ${ }^{2}$ \\ ${ }^{1}$ Centro de Investigación en Materiales Avanzados, S.C., Chihuahua, C.P. 31109, México \\ ${ }^{2}$ Departamento de Investigación en Física de la Universidad de Sonora, Hermosillo, Sonora, C.P. 83000, México \\ ${ }^{3}$ Facultad de Ingeniería Química, Universidad Michoacana de San Nicolás de Hidalgo, Morelia, Michoacán, \\ C.P. 58030 , México \\ ${ }^{4}$ Centro de Nanociencias y Nanotecnología, Universidad Nacional Autónoma de México, Ensenada, Baja California, \\ C.P. 22800, México
}

MS received 6 November 2013; revised 14 January 2014

\begin{abstract}
The improvement of the growth of thick GaN films using a fused silica wafer covered with a thin gold layer by chemical vapour deposition at $800{ }^{\circ} \mathrm{C}$ is reported. In order to compare the surface properties, crystalline quality, micromilling performance and luminescence, the characterization of a GaN film grown on a silicon wafer is presented as well. The different morphologies of the surface observed on the GaN films are compared on each substrate and the resulting microstructures are presented in detail. High resolution TEM images of the GaN films show the main crystallographic planes characterizing these structures. The wurtzite structure was determined for each sample using the substrates of $\mathrm{Au} / \mathrm{SiO}_{2}$ and $\mathrm{Si}(100)$ from the XRD patterns. Also, the re-deposition effect after ion milling of the GaN films is reported. The performance of ionic beam on the surface of the GaN thick films for the geometries patterning of rectangular, circular and annular with two different ion doses was compared. Cathodoluminescence spectra showed that the top surfaces of the samples emit strong UV emissions peaked at 3.35 and $3 \cdot 32 \mathrm{eV}$ which are related to the $Y_{4}$ and $Y_{6}$ transitions.
\end{abstract}

Keywords. Gallium nitride; gold layer; fused silica; silicon; substrate.

\section{Introduction}

Gallium nitride $(\mathrm{GaN})$ and their alloys ( $\mathrm{InGaN}-\mathrm{AlGaN})$ have found important applications due to their broad band gap $(3.4 \mathrm{eV})$ suitable for high power electronics, light emitting diodes, sensors and solar cells (Hwa-Mok et al 2004; Dong et al 2009; Chen et al 2012; Chang-Ju et al 2013). Initially, the gallium nitride was developed as powder material but the development of their applications in optoelectronics gradually decreased the attention of researchers.

The technical difficulties inherent to the handling as a powder and the control of their physicochemical properties, allowed the development of thick or thin films of these compounds, which was more practical and reproducible. As a result, $\mathrm{GaN}$ has established more remarkable results on films technology and their wide expansion into the optoelectronics devices at blue and ultraviolet wavelengths (Li et al 2006; Sun et al 2010).

Currently, the high-quality GaN films have been grown through several techniques such as metal-organic chemical vapour deposition (MOCVD) and molecular beam epitaxy (MBE) (Hughes et al 1995; Chul-Woo et al 1999; MartinezCriado et al 2000; Hersee et al 2006; Thillosen et al 2006;

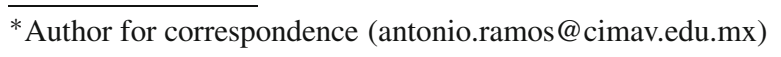

Richter et al 2008; Sobanska et al 2012). By means of these growth methods, the improvement of luminescence efficiency in the GaN-based devices was characterized on various substrates. Despite of the high dislocation density obtained, the quality of $\mathrm{GaN}$ has been improved using the sapphire substrate. However, the search of a suitable substrate for this nitride is still in discussion and other candidates have been proposed for $\mathrm{GaN}$ epitaxy such as $\mathrm{ZnO}, \beta$-SiC, BP, GaAs, GaP, Si, $\mathrm{MgAl}_{2} \mathrm{O}_{4}, \mathrm{MgO}, \gamma-\mathrm{LiAlO}_{2}, \mathrm{ZrN}, \mathrm{ScN}$ and TiN (Liu and Edgar 2002).

Besides of the research on the growth techniques for the gallium nitride, the influence of the substrate on the crystalline, electron, optical and compositional properties of the $\mathrm{GaN}$ deposition is still in discussion, which motivates to discover new routes to improve the quality of gallium nitride films. The present work reports the results on the surface morphology, crystalline structure, milling pattern and optical emission of $\mathrm{GaN}$ films grown by chemical vapour deposition at $800{ }^{\circ} \mathrm{C}$. To compare the GaN properties under different substrates, a fused silica wafer covered with a thin gold layer $\left(\mathrm{Au} / \mathrm{SiO}_{2}\right)$ and a wafer of monocrystalline silicon $(\mathrm{Si})$ are used. Using scanning electron microscopy (SEM), the formation of segregates and irregular polyhedral in the surface of $\mathrm{GaN}$ films on the substrates of $\mathrm{Au} / \mathrm{SiO}_{2}$ and $\mathrm{Si}$ were found. By means of transmission electron microscopy (TEM), high 


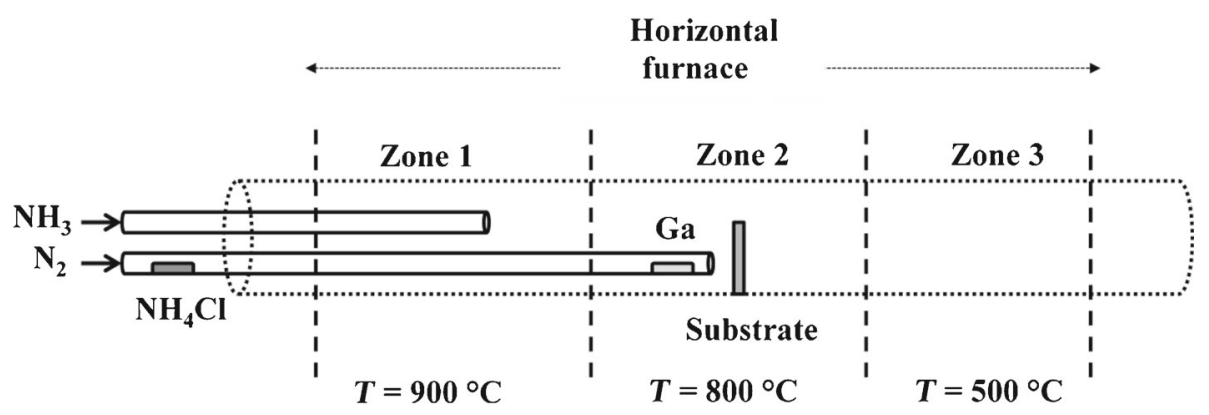

Figure 1. Schematic diagram of the CVD horizontal reactor used for the growth of GaN films on $\mathrm{Au} / \mathrm{SiO}_{2}$ and $\mathrm{Si}$ substrates.

resolution images and interplanar distances were obtained for $\mathrm{GaN}$ films. To study the crystalline structure, X-ray patterns were analysed for both samples and their average grain size was calculated from X-ray diffraction (XRD) experimental data. In order to characterize the gallium nitride films with regard to the probability of forming submicron structures, 2D milling patterns were performed by using focus ion beam (FIB). Two broad emissions peaked at 3.35 and 3.32 $\mathrm{eV}$ related to the $\mathrm{Y}_{4}$ and $\mathrm{Y}_{6}$ transitions were obtained in the GaN films by cathodoluminescence (CL).

\section{Experimental}

Thick GaN films under study were grown by chemical vapour deposition at $800{ }^{\circ} \mathrm{C}$ on two different substrates: (i) a fused silica wafer covered with a gold layer $\left(\mathrm{Au} / \mathrm{SiO}_{2}\right)$ and (ii) a silicon wafer. Figure 1 presents a schematic diagram of the CVD system showing the main zones and set up of the growth process. The CVD system consists of a horizontal quartz tube of $2 \frac{1}{2}$ " diameter divided in three zones. Additionally, two concentric tubes of $\frac{3}{4}$ " diameter were used for the introduction of high purity ammonia $\left(\mathrm{NH}_{3}\right)$ and nitrogen $\left(\mathrm{N}_{2}\right)$ as carrier gases. Two containers with ammonia chloride salt $\left(\mathrm{NHCl}_{4}\right)$ and metallic gallium $(\mathrm{Ga})$ are located at the entrance of the zone 1 and the middle of the zone 2 of the CVD system, respectively. The GaN deposition on the substrate occurs based on the decomposition of $\mathrm{NH}_{4} \mathrm{Cl}$ and the formation of volatile chloride $(\mathrm{GaCl})$ compound (Garcia et al 2008; Ramos-Carrazco 2013). The growth process for the deposition of $\mathrm{GaN}$ on both $\mathrm{Au} / \mathrm{SiO}_{2}$ and $\mathrm{Si}$ substrates was performed at atmospheric pressure using a nitrogen flux of $200 \mathrm{sccm}$ and an ammonia flux of $300 \mathrm{sccm}$.

Two types of substrates based on amorphous and crystalline materials were used for the growing process of $\mathrm{GaN}$ films by means of the CVD method. Both substrates were treated with a chemical cleaning solution using an ultrasonic bath of $35 \%$ hydrofluoric acid to remove impurities. After that, a thin Au layer of approximately $50 \mathrm{~nm}$ was deposited on a fused silica wafer of $25.6 \mathrm{~mm}$ diameter by means of sputtering. For the second sample, a silicon wafer of $50 \mathrm{~mm}$ diameter with a resistivity of $1-10 \Omega \mathrm{cm}^{-1}$ was used as substrate. Before the deposition, each substrate was placed in zone 2 and a heat treatment was applied at $800{ }^{\circ} \mathrm{C}$ for $1 \mathrm{~h}$ under vacuum conditions.

The morphology of the surface of GaN films was obtained by means of a JEOL 5300 scanning electron microscope. Also, the root mean square (rms) roughness of gallium nitride films was measured using a JSP-4210 JEOL atomic force microscope (AFM). High resolution images were recorded in a Tecnai Philips F20 transmission electron microscope. The XRD patterns were performed with a D500 Siemens diffractometer in a range of $20-70^{\circ}(2 \theta)$ at room temperature using a wavelength of $1.54 \AA$, at $45 \mathrm{KV}$ and $30 \mathrm{~mA}$. The 2D patterns were obtained in a multibeam JIB- 4500 focus ion beam with doses of 10 and $5 \mathrm{nC} / \mu \mathrm{m}^{2}$ and a voltage acceleration of $30 \mathrm{KV}$. The cathodoluminescence spectra of the GaN films were recorded in a JEOL JSM 6300 SEM with a voltage acceleration of $5 \mathrm{KV}$ and current of $300 \mathrm{pA}$ at room temperature.

\section{Results and discussion}

Figure 2 shows the SEM images of the GaN thick films grown by chemical vapour deposition during $60 \mathrm{~min}$ on $\mathrm{Au} / \mathrm{SiO}_{2}$ and $\mathrm{Si}$ substrates. The formation of multiple segregates with a diameter between 1 and $10 \mu \mathrm{m}$ were obtained in the $\mathrm{GaN}$ film using $\mathrm{Au} / \mathrm{SiO}_{2}$ substrate, as is presented in figure 2(A). The surface in a coalescence stage is related to the use of the gold layer and the formation of droplets after annealing, which promote the solid-liquid-vapour mechanism in the GaN film. To analyse GaN segregates, an energy dispersive X-ray spectrum was performed and absence of oxygen or pure metals was found. From figure 2(B), a uniform thickness of $5 \mu \mathrm{m}$ of the GaN film grown on $\mathrm{Au} / \mathrm{SiO}_{2}$ substrate is presented by means of a cross-section SEM image. For the silicon substrate, an increment of the size of $\mathrm{GaN}$ structures was obtained without larger accumulations, as shown in figure $2(\mathrm{C})$. This film exhibits irregular polyhedra with hexagonal and triangular formations with diameters and facets lengths from 1 to $5 \mu \mathrm{m}$ respectively. However, the top facet of the triangular shape was only observed for small crystals, while the hexagonal shape was observed on larger crystals. This phenomenon has been also reported on the growth of $\mathrm{GaN}$ nanoislands on $\mathrm{Si}$-rich $\mathrm{SiN}_{x}$ and is 

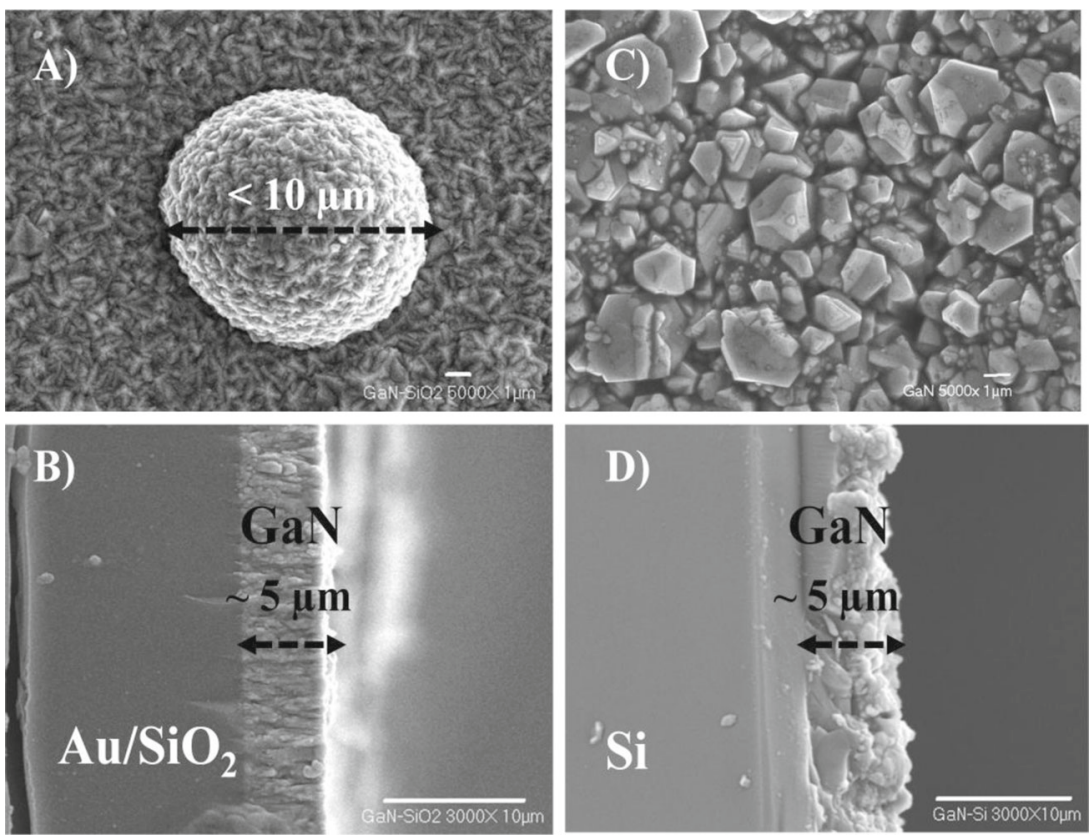

Figure 2. Plane-view SEM images of polycrystalline gallium nitride films grown on (A) $\mathrm{Au} / \mathrm{SiO}_{2}$ and (C) $\mathrm{Si}$ substrates. Cross-section images and estimated thickness of the $\mathrm{GaN}$ layers deposited on (B) fused silica and (D) silicon substrates.
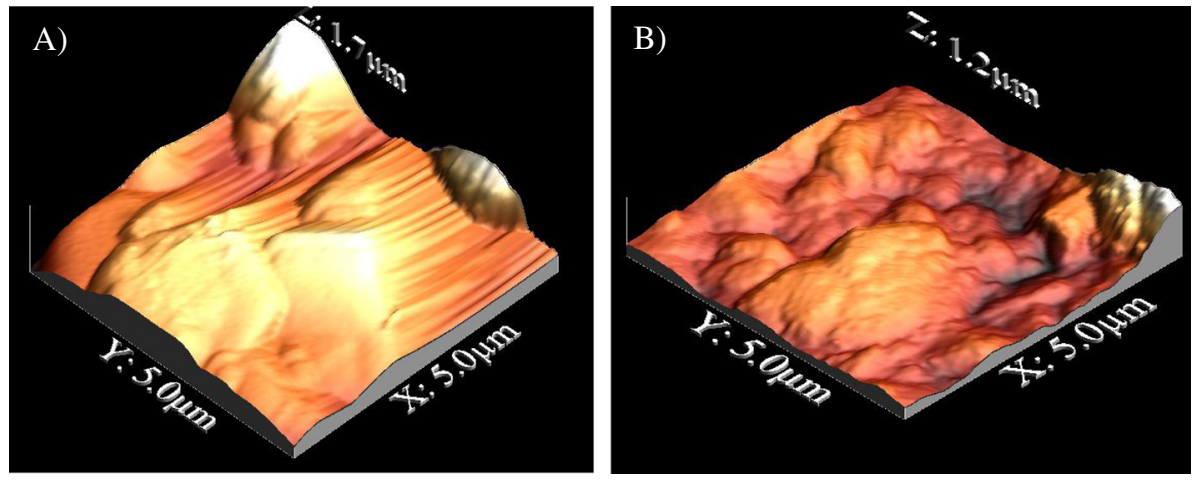

Figure 3. AFM images illustrating the morphology surface for (A) $\mathrm{GaN}$ grown on $\mathrm{Au} / \mathrm{SiO}_{2}$ substrate and (B) GaN grown on Si substrate. Scan size of $5 \times 5 \mu \mathrm{m}$.

related to the change of the island size and the annealing of the nucleations layers (Fang and Kang 2007). In comparison with the GaN grown on the $\mathrm{Au} / \mathrm{SiO}_{2}$ substrate, the thickness of the $\mathrm{GaN}$ film on $\mathrm{Si}$ is highly asymmetrical and porous with a maximum width of $5 \mu \mathrm{m}$ approximately, as shown in figure 2(D). Figure 3 shows atomic force microscopy measurements were used to obtain the surface morphology. For gallium nitride deposited on $\mathrm{Au} / \mathrm{SiO}_{2}$ substrate $\left(5 \times 5 \mu \mathrm{m}^{2}\right)$ a rms roughness of $156 \mathrm{~nm}$ in the surface was obtained while the nitride grown on silicon wafer shows an increment in the roughness of $274 \mathrm{~nm}$.

Figure 4 presents two high resolution TEM images of $\mathrm{GaN}$ films grown on $\mathrm{Au} / \mathrm{SiO}_{2}$ and $\mathrm{Si}$ substrates. For the first sample, the crystallographic plane (002) was identified and indexed using the corresponding interplanar distance of the gallium nitride according to the ICDD card database 00-0500792, as shown in figure 4(A). From figure 4(B), the diffraction pattern showing a hexagonal shaped geometry with three crystalline orientations related to the crystallographic planes (100), (002) and (101) was obtained in the GaN film grown on silicon substrate.

Figure 5 contains the XRD patterns obtained in $\mathrm{GaN}$ films grown on $\mathrm{Au} / \mathrm{SiO}_{2}$ and $\mathrm{Si}$ substrates. The $\theta-2 \theta$ scan confirms that both GaN films present a wurtzite crystalline structure according to the ICDD card database 00-050-0792. Figure 5(A) displays the single XRD peak obtained in the thick GaN film using the $\mathrm{Au} / \mathrm{SiO}_{2}$ substrate at $2 \theta=34.3^{\circ}$ corresponding to the (002) $c$-plane. No other crystalline phases were present as shown in the XRD characterization for this GaN sample, either such as pure metals or oxides. 

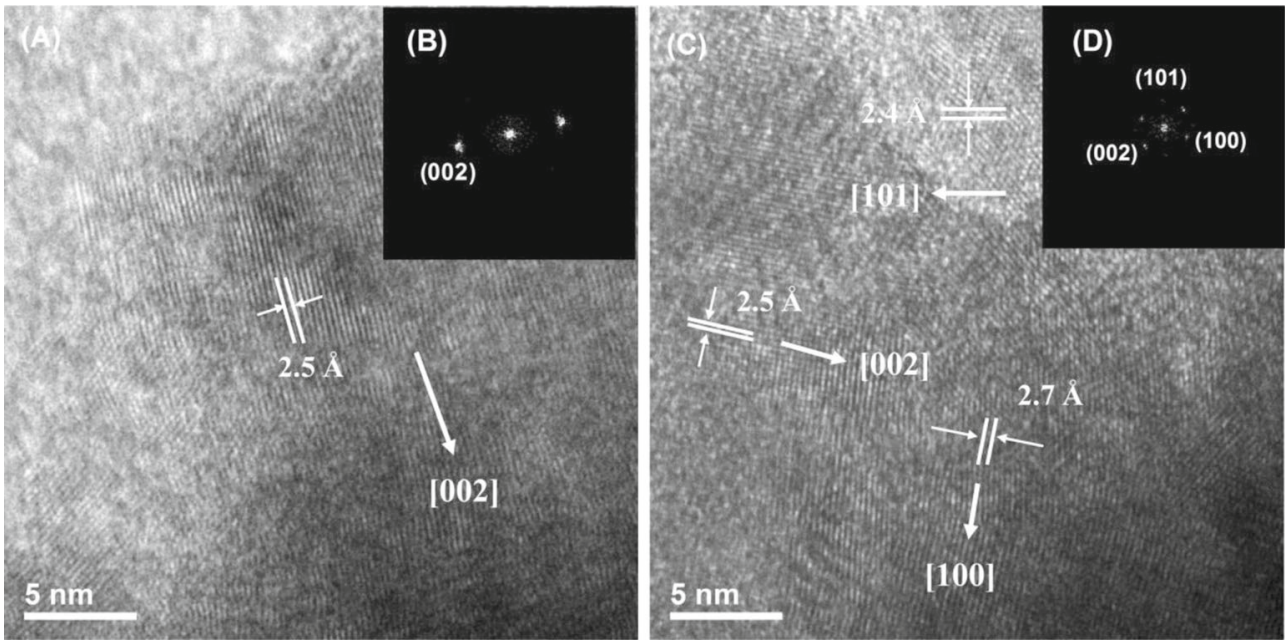

Figure 4. High-magnification TEM images (A and $\mathbf{C})$ and crystallographic planes (B and $\mathbf{D})$ observed in the $\mathrm{GaN}$ crystallites grown on $\mathrm{Au} / \mathrm{SiO}_{2}$ and $\mathrm{Si}$ substrates.
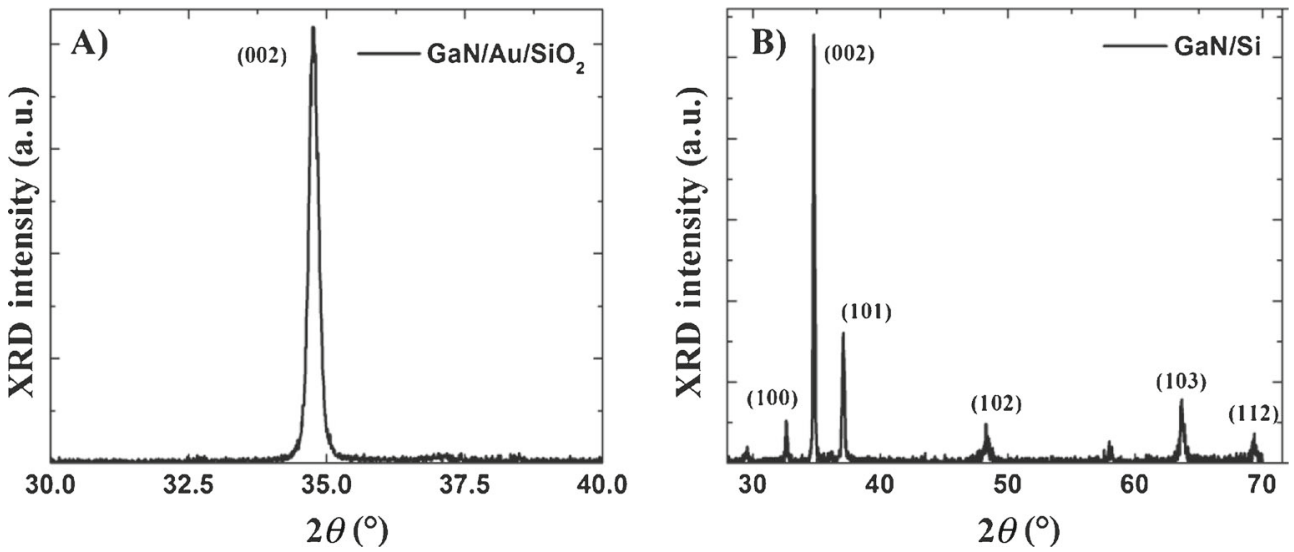

Figure 5. XRD patterns of GaN films obtained by chemical vapour deposition at $800{ }^{\circ} \mathrm{C}$ using two different substrates.

Figure 5(B) shows the XRD pattern of the gallium nitride grown on $\mathrm{Si}$ wafer, showing one intense diffraction peak at $34.7^{\circ}$ and five weaker peaks at $32 \cdot 6,37 \cdot 1,48 \cdot 2,63 \cdot 3$ and $69.3(2 \theta)$ degrees corresponding to (002), (100), (101), (102), (103), (112) planes, respectively. The high intensity of the XRD peaks from the $c$-plane on both GaN films demonstrates the preferential direction orientated in the basal plane. However, the fact that the $\mathrm{GaN}$ grown on $\mathrm{Au} / \mathrm{SiO}_{2}$ appears to suppress the rest of the crystallographic planes, suggest a good control of crystalline quality because of the gold layer. Establishing as reference, the $c$-plane (002) for both samples, through the full width at half maximum (FWHM) corresponding to every sample, the mean crystallite size was calculated for $\mathrm{GaN}$ films using the Scherrer equation. For the gallium nitride grown on $\mathrm{Au} / \mathrm{SiO}_{2}$ substrate, the average crystal size was $1.5 \mathrm{~nm}$ while for the specimen grown on Si substrate, their crystal size was about $1.1 \mathrm{~nm}$. From these results, the quality of the GaN deposited on crystalline silicon is comparable to that obtained on fused silica covered with a gold layer.

Figure 6 presents four 2D patterns produced on the surface of GaN films by means of focus ion beam. A rectangular milling $(10 \times 2 \mu \mathrm{m})$ applied to one $\mathrm{GaN}$ segregation obtained on the $\mathrm{Au} / \mathrm{SiO}_{2}$ substrate using a dose of $5 \mathrm{nC} / \mu \mathrm{m}^{2}$ is shown in figure 6(A). Despite the emergence of GaN spheres, the segregated one exhibits a superficial level with respect to the GaN film which is sensitive to low dose of the ion beam. In order to establish a comparison, a circular milling (radii $=5 \mu \mathrm{m}$ ) was produced selecting other $\mathrm{GaN}$ sphere, but using an increment of the dose up to $10 \mathrm{nC} / \mu \mathrm{m}^{2}$, as presented in figure 6(B). As a result, the complete ablation of the GaN segregation was obtained with some re-deposited zones around the devastated area. From figure $6(\mathrm{C})$, a milling pattern $(10 \times 2 \mu \mathrm{m})$ for the GaN film grown on silicon substrate with a dose of $10 \mathrm{nC} / \mu \mathrm{m}^{2}$ is presented. For this rectangular geometry, a well-defined pattern with low 

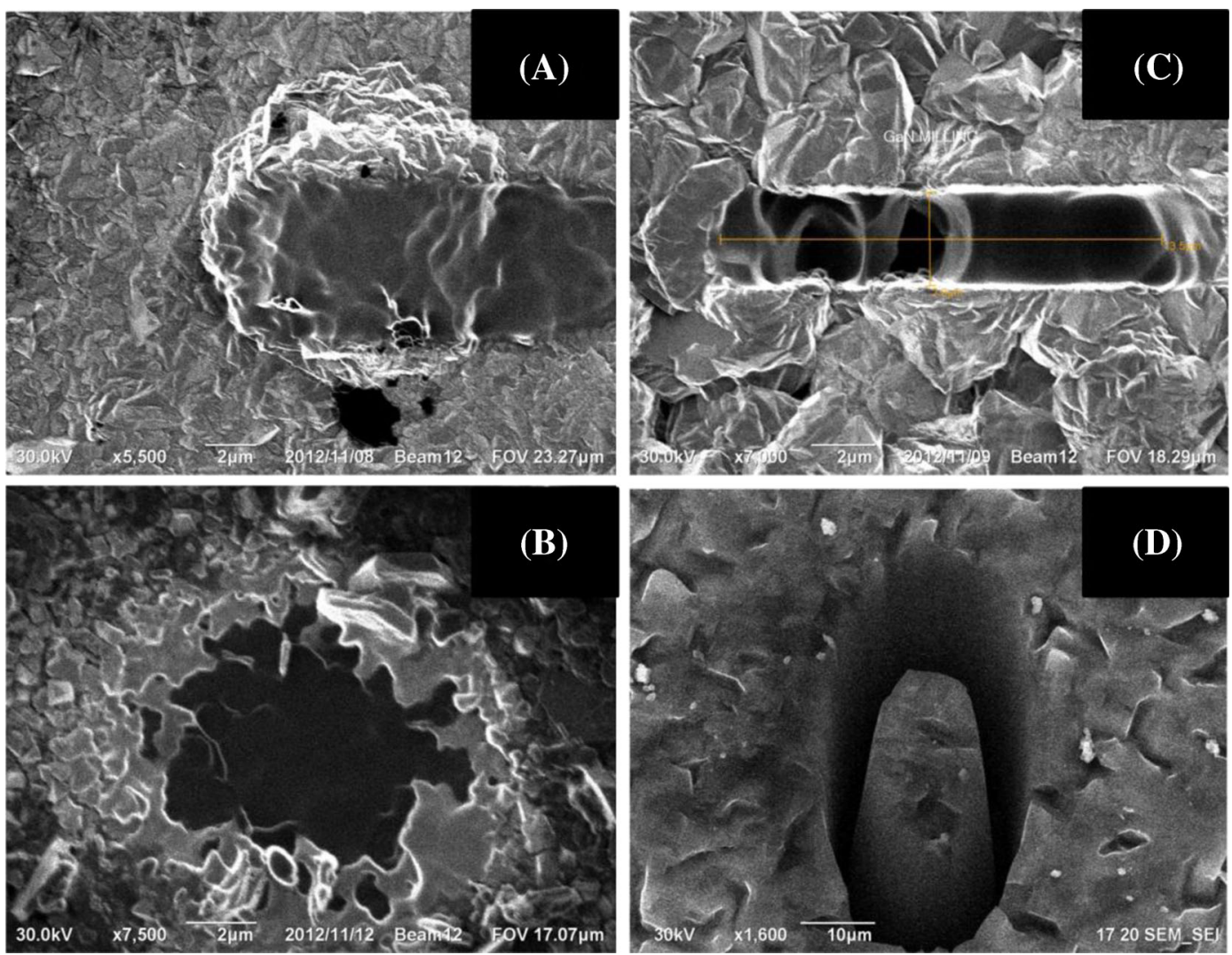

Figure 6. Secondary electron images showing FIB 2D patterns applied to the segregates and coalescing surface in the GaN films. (A) Rectangular and (B) circular patterns with doses of 5 and $10 \mathrm{nC} / \mu \mathrm{m}^{2}$ performed on $\mathrm{Au} / \mathrm{SiO}_{2}$ substrate. (C) Rectangular and (D) annular patterns realized on Si substrate.

re-deposition zones at the edges was obtained. To evaluate the damage of the surface on this $\mathrm{GaN}$ film, a different milling pattern with an annular $(20 \mu \mathrm{m}$ of external diameter) geometry was achieved, as demonstrated in figure 6(D). From these results, it becomes evident that gallium nitride grown on silicon wafer presents lower material re-deposition around the patterns, even with larger milling sections. Although, this work is focused on the comparison of two different substrates on the growth of GaN films, this characteristic issue should be studied profusely to expand the knowledge in the fabrication of patterned masks.

Figure 7 exhibits the CL spectra of GaN films grown on $\mathrm{Au} / \mathrm{SiO}_{2}$ and silicon substrates at room temperature. The $\mathrm{Y}_{4}$ line emission of approximately $370 \mathrm{~nm}(3.35 \mathrm{eV})$ at $300 \mathrm{~K}$ was obtained in the $\mathrm{GaN}$ film grown on $\mathrm{Au} / \mathrm{SiO}_{2}$. Commonly, this peak is related to excitons bound to structural defects at the surface on undoped GaN. However, for this GaN sample the $\mathrm{Y}_{4}$ emission presents a FWHM with higher value of $20 \mathrm{meV}$ which exceeds previous reports. On the silicon substrate, a broader peak with higher intensity at $373 \mathrm{~nm}(3.32 \mathrm{eV})$ was obtained in the GaN film. In this case, this optical transition is known as the $\mathrm{Y}_{6}$ line emission and has been associated with a surface donor-acceptor-pair (DAP). Also, this luminescence band is only reported for

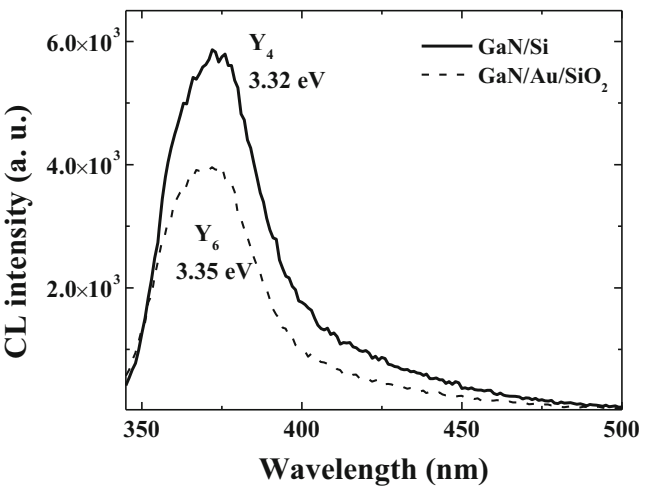

Figure 7. The CL spectra of the GaN films deposited on (A) $\mathrm{Au} /$ $\mathrm{SiO}_{2}$ substrate and (B) Si substrate.

undoped gallium nitride and is typical of films consisting in roughened surfaces.

\section{Conclusions}

In summary, GaN films were grown by chemical vapour deposition on fused silica covered with a thin gold layer 
and also over silicon substrates. For $\mathrm{Au} / \mathrm{SiO}_{2}$ wafer, a decrease of the roughness in the GaN surface with multiple accumulations was obtained, while in crystalline silicon, the formation of irregular polyhedra was observed. Structural analysis of GaN films by means of XRD and TEM shows that the use of a thin Au layer on $\mathrm{SiO}_{2}$ substrate benefits the crystalline growth of the GaN film, despite the amorphous nature of fused silica. Also, the $\mathrm{Au} / \mathrm{SiO}_{2}$ substrate improves the orientation growth on the $\mathrm{GaN}$ towards the $c$-axis and competes with the crystalline quality obtained in the $\mathrm{GaN}$ film deposited on the $\mathrm{Si}$ substrate. From the 2D milling patterns, the silicon substrate demonstrates a decrease of the re-deposition effect on the GaN film after ionic ablation. By using FIB milling, a low depth level of segregations on the surface was found and large quantities of re-deposited material were obtained in the film grown on $\mathrm{Au} / \mathrm{SiO}_{2}$ substrate. $\mathrm{CL}$ measurements for $\mathrm{GaN}$ films show an emission with higher energy for the sample grown on $\mathrm{Au} / \mathrm{SiO}_{2}$ than that obtained on silicon with a slight decrease on the intensity. The $\mathrm{Au} / \mathrm{SiO}_{2}$ substrate reported in this work demonstrates the properties of high crystalline quality and optical emission of a GaN film, which also are comparable with the obtained results in the specimen grown on the $\mathrm{Si}$ substrate.

\section{Acknowledgements}

The authors gratefully acknowledge the use of facilities within the Universidad de Sonora (UNISON), Universidad Michoacana de San Nicolas of Hidalgo (UMSNH), Centro de Nanociencias y Nanotecnología (UNAM) and Centro de Investigación en Materiales Avanzados (CIMAV). This research has been partially supported by CONACyT México, under project number 102671. The authors are grateful to I Gradilla and E Aparico for technical assistance.

\section{References}

Chang-Ju L, Young-Jin K, Chul-Ho W, Jung-Lee L and Sung-Ho H 2013 Appl. Phys. Lett. 103111110

Chen R, Zhou W and Sing-Kwok H 2012 Appl. Phys. Lett. 100 022111

Chul-Woo L, Sung-Taek K, Ki-Soo L, Kasi Viswanath A, Joo In L, Hyung Gyo L, Gye Mo Y and Kee Young L 1999 J. Korean Phys. Soc. 35280

Dong Y, Tian B, Kempa T J and Lieber C M 2009 Nano Lett. 92183

Fang Z and Kang J 2007 J. Phys. Chem. 1117889

Garcia R, Thomas A C and Ponce F A 2008 J. Cryst. Growth 310 3131

Hersee S D, Sun X and Wang X 2006 Nano Lett. 61808

Hughes W C, Rowland W H, Johnson M A L Jr, Fujita S, Cook J W Jr, Schetzina J F, Ren J and Edmond J A 1995 J. Vac. Sci. Technol. B 131571

Hwa-Mok K, Yong-Hoon C, Hosang L, Suk II K, Sung-Ryong R, Deuk-Young K, Tae-Won K and Kwan-Soo C 2004 Nano Lett. 4 1059

Liu L and Edgar J H 2002 Mater. Sci. Eng. R 3761

Martínez-Criado G, Cros A, Cantarero A, Dimitrov R, Ambacher O and Stutzmann M 2000 J. Appl. Phys. 883470

Li D B, Nakamura K, Miyake H, Hiramatsu K, Kobayashi M and Kikuta S 2006 Phys. Status Solid. 82750

Ramos-Carrazco A, Garcia R, Barboza-Flores M and Rangel R 2013. Bull. Mater. Sci. (in press)

Richter T, Lüth H, Meijers R, Calarco R and Marso M 2008 Nano Lett. 83056

Sobanska M, Klosek K, Zytkiewicz Z R, Borysiuk J, Witkowski B S, Lusakowska E, Reszka A and Jakiela R 2012 Cryst. Res. Technol. 47307

Sun G, Ding Y J, Liu G, Huang G S and Zhao H 2010 Appl. Phys. Lett. 97021904

Thillosen N, Sebald K, Hardtdegen H, Meijers R, Calarco R, Montanari S, Kaluza N, Gutowski J and Lüth H 2006 Nano Lett. 6704 